3. Engel AG, Angelini C (1973) Carnitine deficiency of human skeletal muscle with associated lipid storage myopathy: a new syndrome. Science 179:899-902

4. Karpati G, Carpenter S, Engel AG, Watters G, Allen J, Rothman S, Klassen G, Mamer O (1975) The syndrome of systemic carnitine deficiency. Neurology $25: 16-24$

5. Petrykowski W von, Ketelsen U.P, Schmidt-Sommerfeld E, Penn D, Sawicka E, Struck E, Lehnert W, Haap K, Strassburg H-M (1985) Primary systemic carnitine deficiency under successful therapy: clinical, biochemical, ultrahistochemical and renal clearance studies. Clin Neuropathol 4:63-71

6. Tripp M, Katcher ML, Peters HA, Gilbert EF, Arya S, Hodach RJ, Shug AL (1981) Systemic carnitine deficiency presenting as familial endocardial fibroelastosis. N Engl J Med 305:385-390

7. Waber LJ, Valle D, Neill C, DiMauro S, Shug A (1982) Carnitine deficiency presenting as familial cardiomyopathy: a treatable defect in carnitine transport. J Pediatr 101:700-705

Received January 29, 1988

\section{Dried blood spot immunoreactive trypsin (IRT) values}

\author{
F.Pederzini $^{1}$, G.Mastella ${ }^{1}$, L.Giglio ${ }^{2}$, and D.Faraguna ${ }^{2}$ \\ ${ }^{1}$ Cystic Fibrosis Center, Istituti Ospitalieri, Ple Stefani 2, Verona, \\ Italy \\ ${ }^{2}$ Istituto per l'infanzia, Burlo Garofalo Università, Viale dell'Istria, \\ Trieste, Italy
}

Sir: Bourguignon et al. [1] observed no significant differences between dried blood spot immunoreactive trypsin (IRT) values measured during the first 5 days of life. For practical reasons they suggested that blood be obtained for cystic fibrosis $(\mathrm{CF})$ screening on the 5 th day of life. They also referred to five newborns with chronic fetal distress who showed increased IRT levels on the 1st day of life but not later.

It is known that high blood trypsin levels occur in babies with $\mathrm{CF}$, although it must be kept in mind that the test is not specific. Using a cut-off point of $55 \mu \mathrm{g} / \mathrm{l}$ we obtained $1.6 \%$ false-positive results in our study of 69640 babies tested on the 1st day of life.

Studying two groups of 5694 and 5829 newborns on the 1st and 5th day of life, respectively, we found log-normal distributions of IRT values and significant differences of the 99th percentiles, which were $83.2 \mu \mathrm{g} / \mathrm{l}$ on day 1 and $60.3 \mu \mathrm{g} / \mathrm{l}$ on day 5 .

After this study, 40000 newborns were screened on the 5 th day of life. Using a cut-off value of $50 \mu \mathrm{g} / \mathrm{l}$ we found $0.7 \%$ newborns with values exceeding this limit. Thus we conclude that IRT levels are higher on the 1st day of life than on the 5th day and that screening, on day 5 offers the advantage of higher specificity.

In addition, we wish to confirm the observation of Bourguignon et al. [1] about higher IRT levels in sick neonates: $18 \%$ of 477 newborns with an elevated IRT level had a history of perinatal asphyxia.

\section{References}

1. Bourguignon JP, Deby-Dupont G, Reuter A, Senterre J, Gérard A, Franchimont P (1986) Variations in dried blood spot immunoreactive trypsin in relation to gestational age and during the first week of life. Eur J Pediatr 144:547

Received September 24, 1987

\section{Reply}

\section{J.P.Bourguignon}

Centre Hospitalier Universitaire, Clinique Pédiatrique, C. H. U. Sart Tilman, B-4020 Liège, Belgium

We thank Dr. Pederzini and his colleagues for providing an interesting comment on the appropriate age for cystic fibrosis screening. As a matter of fact, we have shown that IRT levels were higher on day 1 than on day 2,3 and 4-5 of life as indicated by the slopes of the correlations between samples obtained at day 1 and those obtained subsequently. In addition, using longitudinal data, we have emphasized that subjects with high IRT levels on day 1 are still in the upper range on day 5. Using a large number of cross-sectional observations, Pederzini and his colleagues address the question whether the screening for cystic fibrosis should be performed on day 1 or on day 5. They confirm that reference values of IRT are higher on day 1 than on day 5 . Consequently, the cut-off limit for screening is higher on day 1 than on day 5. Since Pederzini and his colleagues did not use the same centile value as cut-off limit on day 1 and day 5 , we understand why their false positive rate was higher on day 1 . The critical question is whether or not patient's IRT levels on day 1 are higher than on day 5 and how they compare with the reference values at both times. In this regard, we are curious about IRT levels observed by Pederzini et al. in patients with cystic fibrosis.

Received October 10, 1987

\section{New aspects of oestrogen/gestagen-induced growth and endocrine changes in individuals with Turner syndrome}

\author{
L. Pelz \\ Wilhelm-Pieck-Universität, Klinik für Kinderheilkunde, \\ Rembrandtstrasse 16/17, DDR-2500 Rostock, \\ German Democratic Republic
}

Sir: Based on modern pathogenetic concepts Bohnet [1] has recently described an interesting therapeutic approach to the short stature problem in Turner syndrome. In Fig. 1 the au- 